effect of obesity was negligible. It is surprising that the earlier reports from the Framingham Study ${ }^{5}$ (based on two-year incidence estimates) as well as the 10-year results from the Seven Countries Study ${ }^{4}$ failed to show a convincing relation between obesity and coronary heart disease. A recent report from Framingham, ${ }^{12}$ however, based on 26 -year incidence data, identified obesity as an important and independent risk factor (especially in women).

In the Whitehall Study mortality from causes other than coronary heart disease and cancer was increased by about $50 \%$ in the lowest quintile of body mass index, relative to the middle quintiles. This unexplained finding merits further study.

We are grateful for the co-operation of the Civil Service and their medical advisory service. The work was supported in part by a grant from the British Heart Foundation.

\section{References}

${ }^{1}$ Society of Actuaries. Build and Blood Pressure Study, 1959. Chicago: Society of Actuaries, 1959.

${ }^{2}$ Dyer AR, Stamler J, Berkson DM, Lindberg HA. Relationship of relative body weight and body mass index to 14 -year mortality in the Chicago People's Gas Company Study. $\mathcal{F}$ Chronic Dis 1975;28:108-23.
${ }^{3}$ Lew EA, Garfinkel L. Variations in mortality by weight among 750,000 men and women. $\mathcal{F}$ Chronic Dis 1979;32:563-76.

4 Keys A. Seven countries: a multivariate analysis of death and coronary heart disease. Cambridge, Massachusetts, and London, England: Harvard University Press, 1980.

5 Sorlie P, Gordon T, Kannel WB. Body build and mortality: the Framingham Study. FAMA 1980;243:1828-31.

${ }^{6}$ Reid DD, Hamilton PJS, McCartney P, Rose.G, Jarrett RJ, Keen H. Smoking and other risk factors for coronary heart disease in British civil servants. Lancet 1976 ;ii:979-84.

7 Reid DD, Brett GZ, Hamilton PJS, Jarrett RJ, Keen H, Rose G. Cardiorespiratory disease and diabetes among middle-aged male civil servants. Lancet $1974 ; \mathrm{i}: 469-73$.

${ }^{8}$ Rose G, Shipley MJ. Plasma lipids and mortality : a source of error. Lancet $1980 ; \mathrm{i}: 523-6$.

9 Walker SH, Duncan DB. Estimation of the probability of an event as a function of several independent variables. Biometrika 1967;54:167-79.

10 Larsson B, Björntorp P, Tibblin G. The health consequences of moderate obesity. Int 7 Obes $1981 ; 5: 97-116$.

11 Kagan A, Rhoads G. The relation of mortality to adiposity in youth and middle age. In: Shekelle RB, ed. CVD epidemiology newsletter No 31 of Council of Epidemiology of American Heart Association. New York: AHA, 1982.

12 Hubert HB, Feinlieb M, McNamara PM, Castelli WP. Obesity as an independent risk factor for cardiovascular disease. In: Shekelle RB, ed. CVD epidemiology newsletter No 31 of Council of Epidemiology of American Heart Association. New York: AHA, 1982.

(Accepted 24 fune 1982)

\title{
Randomised controlled trial of nicotine chewing-gum
}

\author{
M J JARVIS，MARTIN RAW，M A H RUSSELL，C FEYERABEND
}

\begin{abstract}
The effectiveness of $2 \mathrm{mg}$ nicotine chewing-gum as an aid to stopping smoking was compared with a placebo containing $1 \mathrm{mg}$ nicotine, but unbuffered, in a double-blind randomised trial. Of 58 subjects given the active gum, 27 $(\mathbf{4 7} \%)$ were not smoking at one-year follow-up compared with $12(21 \%)$ of the 58 subjects treated with placebo $(p<0.025)$. By the most stringent criterion of outcome, $18(31 \%)$ subjects in the active treatment group and eight $(14 \%)$ in the placebo group had not smoked at all from the start of treatment to follow-up at one year $(\mathbf{p}<0.05)$.

Subjects receiving the active gum experienced less severe withdrawal symptoms and rated their gum as more helpful than did the placebo group. Minor side effects were common but only gastric symptoms were more frequent with the active gum. Subjects receiving active gum used it for longer than those receiving placebo but most stopped using it within six months and only four (7\%) developed longer-term dependence. The number of gums used daily correlated significantly with pretreatment blood nicotine concentrations in the active
\end{abstract}

Addiction Research Unit, Institute of Psychiatry, Maudsley Hospital, London SE5

M J JARVIS, BSC, MPHIL, clinical psychologist

MARTIN RAW, BA, MPHIL, clinical psychologist (now at St George's Hospital Medical School, London)

M A H RUSSELL, FRCP, FRCPSYCH, senior lecturer and consultant psychiatrist

Poisons Unit, New Cross Hospital, London SE14

C FEYERABEND, BSC, senior biochemist treatment group and with pretreatment cigarette consumption in the placebo group. A lower pretreatment blood nicotine value was the best predictor of success at one year $(p<0.001)$ but there was no significant relation to cigarette consumption, sex, and social class.

The results clearly confirm the usefulness of nicotine chewing-gum as an aid to stopping smoking and imply a definite role for nicotine in cigarette dependence and withdrawal. Successful use of the gum requires careful attention to subjects' expectations and clear instructions on how to use it.

\section{Introduction}

Many smokers give up smoking without any special help or treatment, but others have great difficulty and fail many times. The first smoking-cessation clinic was started in Stockholm in 1955.1 Since then there has been an intensive search for an effective treatment for dependent smokers. Simple support and encouragement, given individually or in groups, has a success rate of around $15-25 \%$ abstinent at one-year follow-up. ${ }^{2}$ Numerous other methods have been tried, including tranquillisers, ${ }^{3}$ lobeline, ${ }^{4}$ electric aversion therapy, ${ }^{5}$ rapid smoking, ${ }^{6}$ hypnosis, ${ }^{7}$ and, more recently, acupuncture. ${ }^{8}$ None of these methods, however, has been found to have a specific effect over and above the attention-placebo element inherent in any treatment.

We have reported encouraging results from the use of nicotine chewing-gum (Nicorette) in our smokers' clinic. In a comparative study the success rate of smokers who received the gum was $38 \%$ abstinent at one year of follow-up compared with only $14 \%$ of those who had had intensive psychological treatment. ${ }^{9}$ We now report the results of a randomised double-blind placebocontrolled trial of the gum with one-year follow-up and biochemical validation of reported abstinence from smoking. 


\section{Subjects and methods}

The active gum contained $2 \mathrm{mg}$ nicotine and was identical with the commercially available preparation. The placebo gum contained $1 \mathrm{mg}$ nicotine and its biological availability was reduced by the lack of an alkaline buffer to promote absorption through the buccal mucosa. The placebo was designed in this way to mimic the nicotine taste of the active gum without providing an effective pharmacological dose. In pretrial tests the placebo gum did produce appreciable plasma nicotine concentrations with excessive chewing (117 nmol/1 (19 ng/ $\mathrm{ml}$ ) when chewed half-hourly for four hours). This suggests that anyone chewing 20 or more placebo gums a day would get a pharmacologically effective dose. The study could therefore be described as a dose-response study. Whatever terminology is preferred, there is no doubt that the "placebo" provided a fairly stringent test of the pharmacological role of nicotine in the efficacy of the active gum. Both active and placebo gums were packed identically and labelled as $2 \mathrm{mg}$ Nicorette.

A total of 116 subjects were entered into the trial. All were cigarette smokers who attended the Maudsley Hospital smokers' clinic for treatment between November 1979 and October 1980 and who agreed to participate in a trial of nicotine chewing-gum. They were treated in groups of about 10, taken in order from the waiting list, each group being allocated at random to receive either the active or placebo gum. There were 12 groups in all, with each of two therapists treating three active-treatment and three placebo groups. Fifty-eight subjects were assigned to the active gum and 58 to the placebo. Therapists and subjects were blind to the allocation.

Before treatment all subjects completed questionnaires about their smoking and attended an assessment interview at which a blood sample was taken two minutes after finishing a cigarette to determine their baseline smoking values of plasma nicotine. ${ }^{10}$ Expired-air carbon monoxide ${ }^{11}$ or carboxyhaemoglobin ${ }^{12}$ values were also measured. Subjects assigned to the two treatments were well matched in demographic characteristics and pretreatment smoking habits, with the exception that those assigned to the active gum tended to be the heavier smokers $(t=2 \cdot 1 ; \mathrm{p}<0.05$; table I).

TABLE I-Comparison of demographic and pretreatment smoking characteristics of subjects receiving active gum and placebo

\begin{tabular}{lcc}
\hline & $\begin{array}{c}\text { Active gum } \\
(\mathrm{n}=58)\end{array}$ & $\begin{array}{c}\text { Placebo gum } \\
(\mathrm{n}=58)\end{array}$ \\
\hline Mean age (years) & $41 \cdot 0$ & $38 \cdot 4$ \\
No (0) of men in group & $29(50 \cdot 0)$ & $23(39 \cdot 7)$ \\
No (0.) of subjects in social classes I and II & $33(56 \cdot 9)$ & $29(50 \cdot 0)$ \\
Mean No of cigarettes smoked daily & $30 \cdot 9$ & $26.5 *$ \\
Mean plasma nicotine concentration $(\mathrm{nmol} / 1)$ & $199 \cdot 1$ & $22.0 \cdot 7$ \\
Mean carboxyhaemoglobin value $\left({ }^{\circ}{ }_{0}\right)$ & $7 \cdot 2$ & $7 \cdot 0$ \\
\hline
\end{tabular}

$* \mathrm{p}<0.05$. (No other differences statistically significant.)

Conversion: SI to traditional units-Nicotine: $1 \mathrm{nmol} 1 \approx 0 \cdot 16 \mathrm{ng} / \mathrm{ml}$

All subjects were given the same instructions about the gum. They were told that it contained nicotine which would be absorbed through the lining of the mouth as it was chewed, and that it would reduce the craving for cigarettes and help to relieve other withdrawal symptoms. They were warned that it might take a few days to get used to the taste, and that they should not expect it to be a miracle cure that removed the necessity for them to work very hard at stopping. They were encouraged to stop smoking completely on the first day of treatment and told to chew a piece of gum whenever the desire to smoke was particularly strong. No restrictions were placed on the number of gums to be chewed each day. It was recommended that they should use the gum for at least three months before attempting to do without it.

Group meetings were held weekly for one hour for the first six weeks. Attendance was similar in those receiving the active and placebo gums, with 28 and 29 subjects respectively attending three or more meetings. Thereafter subjects attended as needed to collect gum and for follow-up at three months, six months, and one year. At the oneyear follow-up claims of abstinence were validated by measurement of expired air carbon monoxide concentrations. There were no cases of deception. In six subjects assigned to active gum and six assigned to placebo biochemical validation was not done but confirmatory reports were obtained from friends or relatives.

At each attendance subjects completed ratings of withdrawal symptoms, acceptability of their gum, and a check list of potential side effects. They were also given cards to record daily consumption of gum and cigarettes.

Statistical analyses were based on the binomial test, $\chi^{2}$ test, and $t \stackrel{\Phi}{\varrho}$ test. Two-sided tests were used except for the analysis of outcome, $c$ where the one-sided hypothesis that the active gum was superior to $\widehat{\Omega}$ the placebo was tested.

\section{Results}

OUTCOME

The figure shows the success rates of the active and placebo gums. A significant advantage for the active gum emerged as early as two 듬 weeks after the start of treatment, when 39 subjects assigned to the $\bar{\sigma}$ active gum were not smoking as compared with only 26 assigned to $\mathbb{D}$

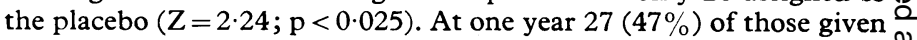
the active gum were abstinent as compared with $12(21 \%)$ of those $\infty$ given the placebo (see table II).

The results were unusual in that there were more subjects abstinent in the active-treatment group at one year than at six months, indicating $\vec{\omega}$ that several subjects who had relapsed at the earlier point stopped $\mathscr{D}$ smoking again before one year. Table II therefore gives the result of $\frac{O}{3}$ applying more stringent criteria of success to supplement the conventional analysis. Whichever criterion of success was applied the $\mathbb{N}$ active gum was clearly more effective than the placebo.

TABLE II-Success rates at one-year follow-up according to three different criteria. (Figures are numbers (\%) of successful subjects)

\begin{tabular}{lllll} 
Criterion of success & $\begin{array}{c}\text { Active } \\
\text { gum } \\
(\mathrm{n}=58)\end{array}$ & $\begin{array}{c}\text { Placebo } \\
\text { gum } \\
(\mathrm{n}=58)\end{array}$ & $\begin{array}{c}\text { Binomial } \\
\text { test } \\
(\mathrm{Z})\end{array}$ & $\begin{array}{c}t \\
(10 \mathrm{df}) *\end{array}$ \\
\hline $\begin{array}{l}\text { Abstinent at one year } \\
\text { Abstinent at end of initial } \\
\text { treatment and at six } \\
\text { months and one year }\end{array}$ & $27(47)$ & $12(21)$ & $2.75 ; \mathrm{p}<0.01$ & $2.31 ; \mathrm{p}<0.025$ \\
$\begin{array}{l}\text { No smoking at all from } \\
\text { first week of treatment } \\
\text { to one year of follow- } \\
\text { up }\end{array}$ & $18(31)$ & $8(14)$ & $2.00 ; \mathrm{p}<0.025$ & $1.92 ; \mathrm{p}<0.05$ \\
\hline
\end{tabular}

Note: One subject receiving active gum was lost to follow-up and classified as a failure despite being abstinent from start of treatment to last contact at five months. * Since treatment was randomised over groups, not individual subjects, group effects could exist which would invalidate use of binomial test. The more conservative $t$ test variance of angular transformation of group success rates.

Of those abstinent at the one-year follow-up, six in the activetreatment group and two in the placebo group were still using the gum. When for the sake of extreme stringency these subjects were excluded from the one-year abstainers, the active gum retained its 0 clear-cut advantage over placebo with $21(36 \%)$ abstinent at one year compared with $10(17 \%)$ of the placebo group $(Z=2.10 ; p<0.05)$. At a mean of 22 months after starting treatment, five of the six subjects given the active gum were still abstinent and three were still using the gum. Both subjects given the placebo had relapsed to smoking.

The figure shows that the main effect of the active gum was to enable more subjects to stop smoking initially. There were also fewer $D$ relapses in the active-treatment group, although this failed to reach음 statistical significance. In the active-treatment group 12 of the 39 subjects abstinent at two weeks had relapsed to smoking at one year, compared with 14 of the 26 in the placebo group $\left(\chi^{2}=2.57 ; \mathrm{df}=1 ; \mathrm{W}\right.$ NS).

\section{QUANTITY AND DURATION OF GUM USE}

Use of the active gum was greater than the placebo at every stage ${ }_{0}^{\circ}$ of treatment and follow-up both in terms of the proportion of subjects $\mathbb{D}$ who were using it and the number of pieces they were chewing a day. The differences, however, were statistically significant only at three and six months (table III). Of the seven subjects using active gum and three using placebo gum at the one-year follow-up, only four, $ᄋ$ all in the active group, had used it continuously throughout the year. The incidence of dependence on the active gum was therefore $7 \%$, and there were no such cases in the placebo group.

Among those who were not smoking at one month there was a 
TABLE III-Comparison of gum use at various times after start of treatment

\begin{tabular}{|c|c|c|c|c|}
\hline \multirow{2}{*}{$\begin{array}{l}\text { Time from } \\
\text { start of } \\
\text { treatment }\end{array}$} & \multicolumn{2}{|c|}{ No $\left({ }^{0} 0\right)$ of subjects using gum } & \multicolumn{2}{|c|}{ Mean No of gums/dayt } \\
\hline & $\begin{array}{c}\text { Active gum } \\
(n=58)\end{array}$ & $\begin{array}{c}\text { Placebo gum } \\
(n=58)\end{array}$ & $\begin{array}{l}\text { Active gum } \\
(\mathrm{n}=58)\end{array}$ & $\begin{array}{l}\text { Placebo gum } \\
(n=58)\end{array}$ \\
\hline $\begin{array}{l}1 \text { week } \\
2 \text { weeks } \\
1 \text { month } \\
3 \text { months } \\
6 \text { months } \\
9 \text { months } \\
1 \text { year }\end{array}$ & $\begin{array}{c}47(81) \\
40(69) \\
33(57) \\
24(41) \\
12(21) \\
5(9) \\
7(12)\end{array}$ & $\begin{array}{c}39(67) \\
36(62) \\
29(50) \\
8\left(14^{*}\right) \\
1\left(2^{*}\right) \\
1(2) \\
3(5)\end{array}$ & $\begin{array}{l}7 \cdot 9 \\
8 \cdot 1 \\
7 \cdot 5 \\
6 \cdot 0 \\
6 \cdot 0 \\
7 \cdot 3 \\
5 \cdot 7\end{array}$ & $\begin{array}{l}6 \cdot 1 \\
6 \cdot 5 \\
5 \cdot 7 \\
3 \cdot 9 \\
2 \cdot 0 \\
4 \cdot 0 \\
3 \cdot 7\end{array}$ \\
\hline
\end{tabular}

$* \mathrm{p}<0.005$. (No other differences between active and placebo groups statistically

+ Number of gums daily are averages for those who were using it.

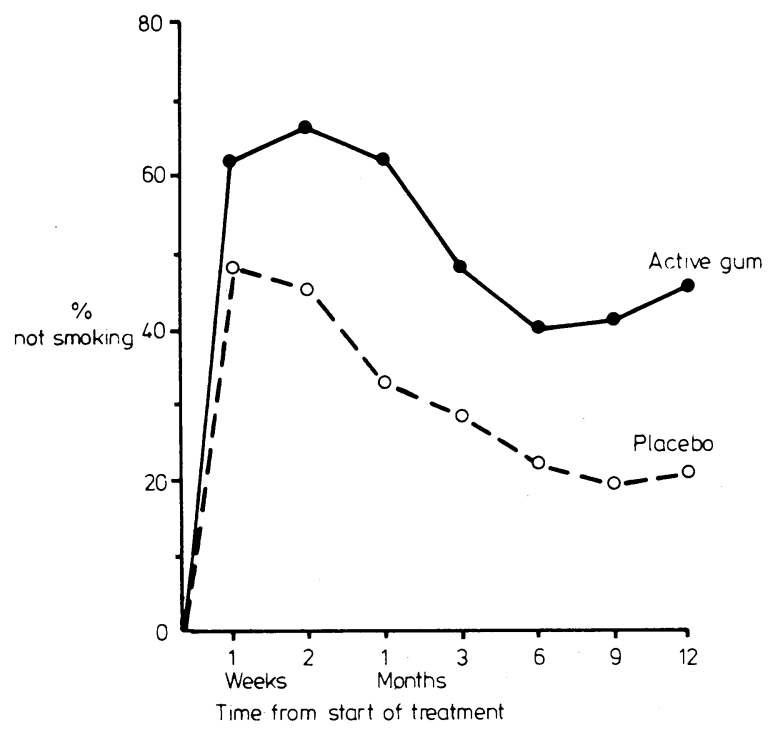

Success rates during treatment and at up to one-year follow-up for subjects receiving active and placebo gums. Percentages based on 58 subjects in each group. Difference at one week not statistically significant; by two weeks significant at $5 \%$ level; at one year significant at $1 \%$ level.

TABLE IV-Incidence of unwanted symptoms reported at least once on check list administered weekly during first six weeks of treatment

\begin{tabular}{|c|c|c|c|c|c|c|c|c|c|c|c|}
\hline & $\begin{array}{l}\text { Felt } \\
\text { sick }\end{array}$ & $\begin{array}{l}\text { Been } \\
\text { sick }\end{array}$ & $\begin{array}{l}\text { Dizzi- } \\
\text { ness }\end{array}$ & 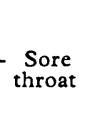 & $\begin{array}{l}\text { Head- } \\
\text { ache }\end{array}$ & $\begin{array}{l}\text { Sore } \\
\text { mouth }\end{array}$ & $\begin{array}{r}\text { Felt } \\
\text { faint }\end{array}$ & $\begin{array}{l}\text { Hic- } \\
\text { cups }\end{array}$ & Indi- & $\begin{array}{l}\text { Tired- } \\
\text { ness } \\
\text { from } \\
\text { chew- } \\
\text { ing }\end{array}$ & $\begin{array}{l}\text { Mouth } \\
\text { ulcers }\end{array}$ \\
\hline $\begin{array}{l}\text { Active } \\
\text { gum } \\
\text { ( } \mathrm{n}=47) \\
\text { Placebo }\end{array}$ & 18 & 2 & 10 & 19 & 14 & 28 & 5 & 14 & 24 & 25 & 1 \\
\hline$\stackrel{\operatorname{gum}}{(n=44)}$ & 9 & 0 & 8 & 17 & 17 & 23 & 3 & $2^{*}$ & $12+$ & 26 & 1 \\
\hline
\end{tabular}

Note: Fewer than 58 subjects in each group owing to early drop-outs. Subjects asked to check whether they had "experienced any of the following this week." $* \mathrm{p}<0.05$.
$+\mathrm{p}<0.01$.

significant correlation between the number of gums used daily at that time and the pretreatment blood nicotine concentration in those assigned to the active gum $(r=0.48 ; n=31 ; p<0.01)$ but not in those assigned to placebo $(r=0 \cdot 17 ; \mathrm{NS})$. Conversely, pretreatment daily cigarette consumption correlated significantly with daily gum use at one month in those receiving the placebo $(\mathrm{r}=0.47 ; \mathrm{n}=19$; $\mathrm{p}<0.05)$ but not in those receiving the active gum $(r=0.11 ; N S)$. Correlations with duration of gum use did not reach statistical significance in either group, though similar trends were evident.

There was a positive relation between duration of gum use and success rate at the one-year follow-up which was evident in both the active-treatment and placebo groups. Of 24 subjects in the active group who chewed the gum for three months or more, 18 were abstinent at one year compared with only nine out of 34 who used it for less than three months. The equivalent figures for the placebo group were five out of eight and seven out of 50 .

\section{SIDE EFFECTS}

Mild and transient symptoms were common with both the active and placebo gums (table IV). They were mainly non-specific effects of heavy chewing. Only in the case of hiccups, indigestion or stomach ache, and feeling sick was the incidence substantially higher and therefore interpretable as specific side effects of the active gum. In most cases these symptoms were mild and transient. In no cases were side effects cited as a cause for discontinuing the gum.

\section{ACCEPTABILITY OF GUM}

Ten subjects in the active-treatment group and 13 in the placebo group did not attend the first meeting after the start of treatment. We do not know whether this was due to dislike of the gum, disappointment with its efficacy, or other reasons. Among the remainder the active group rated the gum as significantly stronger $(p<0.05)$ and more helpful $(p<0.05)$ than the placebo group. Both groups rated the gum as moderately satisfying and slightly unpleasant tasting, and these ratings did not differ significantly between the two groups when averaged over the first six weeks of treatment. In the first week, however, the active group rated their gum as tasting more unpleasant than did the placebo group ( $p<0.05)$, a difference which disappeared by the second week. By the second week the active group found the gum more satisfying than did the placebo group $(\mathrm{p}<0.05)$.

\section{WITHDRAWAL SYMPTOMS}

Since the pattern of attendance at weekly treatment sessions did not differ between the active-treatment and placebo groups, each subject's ratings of withdrawal symptoms over the first six weeks of treatment were averaged. Subjects who received the active gum experienced less severe withdrawal symptoms than the placebo group. They felt less irritable $(p<0.05)$, less sleepy $(p<0.01)$, and less hungry $(p<0.05)$. Differences between the groups in ratings of tenseness, feeling miserable, and difficulty doing without cigarettes also favoured the active gum but did not reach statistical significance. The active group, however, also rated themselves as less alert but this difference was not significant.

\section{CHARACTERISTICS OF SUBJECTS AND OUTCOME}

The relation of the variables listed in table I to outcome at the one-year follow-up was similar in the active-treatment and placebo groups, so that the two groups were combined to provide 39 successes and 77 failures. The successes tended to be older (mean ages $43 v 38$ years; $\mathrm{p}<0.05)$ and to have lower pretreatment carboxyhaemoglobin values (mean $6.0 \%$ v $7.6 \% ; \mathrm{p}<0.01$ ) and lower plasma nicotine concentrations (mean $172.0 \mathrm{nmol} / 1 \quad(27.9 \mathrm{ng} / \mathrm{ml})$ v $229.3 \mathrm{nmol} / \mathrm{l}$ $(37.2 \mathrm{ng} / \mathrm{ml}) ; \mathrm{p}<0.001)$. Their mean pretreatment daily cigarette consumption was also lower $(26.3 v 29.9)$ but this difference was not statistically significant. Social class and sex had no relation to outcome. The success rate among the men was $37 \%$ (19/52) compared with $31 \%(20 / 64)$ for the women $\left(\chi^{2}=0.36 ; \mathrm{NS}\right)$.

\section{Discussion}

Treatment with the active nicotine chewing-gum achieved results that were substantially better than with the placebo. Success rates, based on three different criteria, were more than double those obtained with placebo. By the conventional criterion of smoking status at follow-up $47 \%$ of the subjects in the active-treatment group were abstinent at one year compared with $21 \%$ of the subjects given placebo. By the criterion of abstinence at the end of treatment and at six months and one year the success rates were $38 \%$ and $16 \%$ respectively, and when based on lapse-free abstinence throughout the year from the first week of treatment to the one-year follow-up 
they were $31 \%$ and $14 \%$ respectively. The differences were statistically significant in all three cases and were of a similar order to our earlier study, which obtained a $38 \%$ success rate (conventionally defined) with nicotine chewing-gum compared with $14 \%$ for intensive psychological treatments. ${ }^{9}$ In both studies the active gum alone gave results that were well above the range (about 15-25\%) reported for all other methods. ${ }^{2}$

Our study was unusual in showing a better result at one year than at six months. This was because some subjects who relapsed returned for further treatment. This response contrasts with studies of other treatment methods, in which those who relapse tend to avoid returning even for follow-up. The tendency for those treated with nicotine gum to be more likely to return for a second course if they relapse may be a further reflection of its greater efficacy.

The rigorous design of our study with randomised allocation, double-blind placebo control, success rates based on all who started treatment, biochemical validation of reported abstinence, and the fact that the placebo provided nicotine to taste but with low biological availability all make it difficult to see how the gum could have achieved its effect other than by a specific action of the nicotine it provided. This further suggests an important role for nicotine in maintaining the habit of dependent smokers. That the active gum was significantly more effective in relieving withdrawal symptoms also supports the view that they may be caused partly by nicotine deprivation.

Another finding also has possible implications for the role of nicotine in smoking. This is that the extent of gum use was significantly related to pretreatment plasma nicotine values but not to cigarette consumption in those given the active gum, whereas the reverse was true for those using the placebo. This suggests that the active gum was fulfilling a pharmacological need while the placebo may have been acting more as an oral substitute. The pharmacological role of nicotine is also supported by the fact that $7 \%$ of those assigned to receive the active gum developed some degree of dependence on it, while there were no instances of dependence on the placebo.

On the practical side, the active gum was apparently more effective in helping smokers to stop smoking during the first four weeks of treatment than in reducing the tendency to relapse thereafter. Other studies have found higher rates of long-term success among those who continued using the gum for longer periods. ${ }^{913}$ While it was realised that this may have been attributable to self-selection with people continuing to chew while they were successfully keeping off cigarettes but giving up the gum as soon as they relapsed to smoking, this finding was nevertheless used as a reason for suggesting that longer-term use of the gum might innprove outcome. ${ }^{14}$ That our placebo group also showed a similar trend in this direction suggests that further study is needed to establish the optimal duration of gum use.

We emphasise that the high success rate achieved in this study was not necessarily due to the gum alone. The subjects had six group meetings with an experienced therapist. Above all they were given careful instructions on what they might realistically expect from the gum and how to use it correctly. This no doubt accounted for the lack of more than mild and transient side effects. That the active gum was initially more unpleasant to taste but subsequently became more satisfying points to the importance of encouraging subjects to persist with it for at least two weeks.

We conclude that after more than 20 years of unsuccessful research into all kinds of treatment methods for smokers, nicotine chewing-gum given to well-motivated smokers in a clinic setting is the first treatment to have been developed that has a specific effect over and above that attributable to an attention-placebo response. That it is also the first treatment to provide effective nicotine substitution has important implications for the role of nicotine in cigarette dependence.

We thank the Medical Research Council and Department of Health and Social Security for financial support, A B Leo for supplying the nicotine and placebo gum, and Vera Amato for secretarial help. Our colleagues Gill Devitt, John Stapleton, Steve Sutton, Colin Taylor, and Robert West gave helpful comments.

\section{References}

1 Ejrup B. Proposals for treatment of smokers with severe clinical symptoms brought about by their smoking habit. British Columbia Medical fournal 1960;2:441-53.

${ }^{2}$ Raw M. The treatment of cigarette dependence. In: Israel Y, Glaser FB, Kalant H, Popham RE, Schmidt W, Smart RG, eds. Research advances in alcohol and drug problems. Vol. 4. New York; Plenum, 1978:441-85.

3 Schwartz JL, Dubitsky M. Maximising success in smoking cessation methods. Am $\mathcal{F}$ Public Health 1969;59:1392-9.

- British Tuberculosis Association. Smoking deterrent study. Br Med $\mathcal{J}$ 1963 ;ii :486-7.

5 Russell MAH, Armstrong E, Patel UA. Temporal contiguity in electric aversion therapy for cigarette smoking. Behav Res Ther 1976;14:103-23.

${ }^{6}$ Raw M, Russell MAH. Rapid smoking, cue exposure and support in the modification of smoking. Behav Res Ther 1980;18:363-72.

${ }^{7}$ Berkowitz B, Ross-Townsend A, Kohberger R. Hypnotic treatment of smoking: the single-treatment method revisited. Am $\mathcal{f}$ Psychiatry $1979 ; 136: 83-5$

${ }^{8}$ Lamontagne Y, Annable L, Gagnon MA. Acupuncture for smokers: lack of long-term therapeutic effect in a controlled study. Can Med Assoc $\mathcal{F}$ $1980 ; 122: 787-90$.

${ }^{9}$ Raw M, Jarvis MJ, Russell MAH. Comparison of nicotine chewing-gum and psychological treatments for dependent smokers. Br Med f 1980; $281: 481-2$

${ }^{10}$ Feyerabend C, Russell MAH. Assay of nicotine in biological materials: sources of contamination and their elimination. $\mathcal{F}$ Pharm Pharmacol $1980 ; 32: 178-81$.

11 Jarvis MJ, Russell MAH, Saloojee, Y. Expired air carbon monoxide: a simple breath test of tobacco smoke intake. Br Med f 1980;281:484-5.

12 Russell MAH, Cole PV, Brown E. Absorption by non-smokers of carbon monoxide from room-air polluted by tobacco smoke. Lancet 1973;i : 576-9.

13 Wilhelmson L, Hjalmarson A. Smoking cessation experience in Sweden. Canadian Family Physician 1980;26:737-47.

14 Russell MAH, Raw M, Jarvis MJ. Clinical use of nicotine chewing-gum Br Med F 1980;280:1599-1602.

(Accepted 24 Fune 1982) .

\section{.}

\section{.}

THE OAK is so well known (the timber thereof being the glory and safety of this nation by sea) that it needs no description.

Jupiter owns the tree. The leaves and bark of the Oak, and the acorn cups, do bind and dry very much. The inner bark of the tree, and the thin skin that covers the acorn, are most used to stay the spitting of blood, and the bloody-flux. The decoction of that bark, and the powder of the cups, do stay vomitings, spitting of blood, bleeding at the mouth, or other fluxes of blood, in men or women; lasks also, and the nocturnal involuntary flux of men. The acorn in powder taken in wine, provokes urine, and resists the poison of venomous creatures. The decoction of acorns and the bark made in milk and taken, resists the force of poisonous herbs and medicines, as also the virulency of cantharides, when one by eating them hath his bladder exulcerated, and voids bloody urine. Hippocrates saith, he used the fumes of Oak leaves to women that were troubled with the strangling of the mother; and Galen applied them, being bruised, to cure green wounds. The distilled water of the Oaken bud, before they break out into leaves is good to be used either inwardly or outwardly, to assuage inflammations, and to stop all manner of fluxes in man or woman. The same is singularly good in pestilential and hot burning fevers; for it resists the force of the infection, and allays the heat: It cools the heat of the liver, breaking the stone in the kidneys, and stays women's courses. The decoction of the leaves works the same effects. The water that is found in the hollow places of old Oaks, is very effectual against any foul or spreading scabs. The distilled water (or concoction, which is better) of the leaves, is one of the best remedies that I know of for the whites in women. (Nicholas Culpeper (1616-54) The Complete Herbal, 1850.) 